\title{
Chelating Competency and Electrochemical Response of a Heterocyclic Phenylhydrazone and its Copper Chelate
}

\author{
VINOD P RAPHAEL, JOBY THOMAS K*, K.S. SHAJU and NIMMY KURIAKOSE \\ Department of Chemistry, St. Thomas' College (University of Calicut), \\ Thrissur, Kerala - 680001, India. \\ ${ }^{*}$ Corresponding author E-mail: drjobythomask@gmail.com \\ http://dx.doi.org/10.13005/ojc/300479
}

(Received: August 26, 2014; Accepted: October 15, 2014)

\begin{abstract}
Heterocyclic compound 3-acetylpyridine phenylhydrazone (APPH) and its copper chelate were synthesized and characterized by spectral, elemental, magnetic and conductance measurements. Investigations showed that APPH behaved as bidentate ligand during chelation. The square planar geometry of the chelate was confirmed by magnetic and optical spectral studies. The detailed electrochemical response of the ligand and chelate were evaluated and reported.
\end{abstract}

Key words: Phenylhydrazone, chelate, square planar, cyclic voltammetry.

\section{INTRODUCTION}

The compounds which possess azomethine linkage or Schiff bases are well-known for its chelating competency. Such molecules and their metal chelates are having wide variety of applications in the pharmaceutical, catalysis, analytical and corrosion field ${ }^{1-15}$. In the present investigation we explored the structure of the 3acetylpyridine phenylhydrazone and its copper chelate using various spectroscopic methods. The electrochemical response of these synthesized compounds was also studied using cyclic voltammetry.

\section{MATERIALS AND METHOD}

3-acetyl pyridine was purchased from Fluka. Phenylhydrazine hydrochloride and cupric acetate were obtained from E. merck. Shimadzu model FT-IR Spectrometer (Model: IR affinity) and Shimadzu UV-visible-1800 spectrophotometer were used for recording infrared and electronic spectra. Mass spectrum of the hydrazone was recorded using QP 2010 model Shimadzu GCMS. ${ }^{1} \mathrm{Hnmr}$ and ${ }^{13} \mathrm{Cnmr}$ spectral studies were carried out on Bruker Avance III HD. 
APPH was synthesized by condensing equimolar mixture of 3-acetylpyridine in ethanol and phenylhydrazine hydrochloride in ethanol water mixture (3:1). The reaction mixture was refluxed for four hours, evaporated nearly to dryness and allowed to cool slowly. The precipitated yellow coloured phenylhydrazone was filtered, washed with ethanol and dried.

The phenylhydrazone APPH (3mmol) in ethanol was heated to reflux, hot ethanolic solution $(3 \mathrm{mmol})$ of metal salt was added and the resulting mixture was refluxed for 5 hours, evaporated, cooled and the chelate separated was filtered.

\section{RESULTS AND DISCUSSION}

\section{Characterization of phenylhydrazone}

In the mass spectrum of APPH, the molecular ion peak was observed at $\mathrm{m} / \mathrm{z}=211$. ${ }^{1} \mathrm{Hnmr}$ spectrum displayed nine signals for nine distinguished hydrogen atoms. The signal appeared at $2.28 \delta$ was due to the methyl protons (Table 1). A weak but broad signal appeared at $9.86 \delta$ was assignable to the $\mathrm{NH}$ proton of phenylhydrazine part. Two dimensional ${ }^{1} \mathrm{H}-{ }^{1} \mathrm{Hnmr}$ spectrum (COSY) was very helpful in identifying different hydrogen atoms (Figure 1). Nine diagonal contours were appeared in the COSY spectrum, for nine different protons of the molecule. Strong off diagonal peaks for $\mathrm{H} 1-\mathrm{H} 2$ \& $\mathrm{H} 1-\mathrm{H} 3$ interactions were emerged in the COSY spectrum, which were originated by the strong ortho coupling. Due to the meta coupling between the protons $\mathrm{H} 5$ and $\mathrm{H} 4$ in the pyridine ring, weak contours were seen in the spectrum. $\mathrm{H} 6-\mathrm{H} 7$ and $\mathrm{H} 5-\mathrm{H} 6$ ortho coupling was confirmed by the strong off diagonal contours.

The signals appeared in ${ }^{13} \mathrm{Cnmr}$ spectrum of APPH were assigned for 11 labelled carbon atoms and given in Table 1. The signal of the azomethine carbon appeared at $137.99 \mathrm{ppm}$. A peak observed at $12.53 p p m$ was assignable to methyl carbon atom. The quaternary carbon atoms labelled 6 and 4 gave their signals 134.88 and $145.07 \mathrm{ppm}$ respectively. On close observation of the molecular structure it is

Table 1: ${ }^{1} \mathrm{Hnmr}$ and ${ }^{13} \mathrm{Cnmr}$ spectral data of APPH

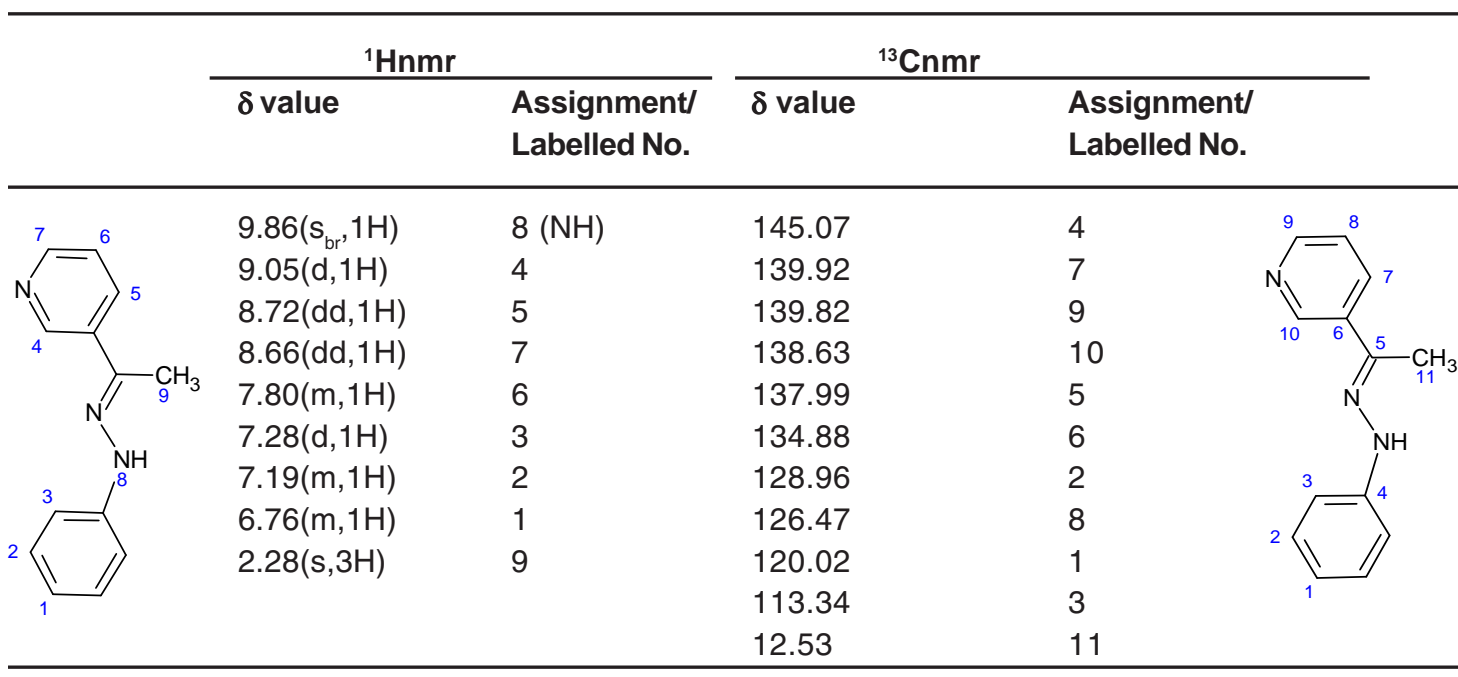

Table 2: Cyclic voltammetric data of APPH

\begin{tabular}{lcccccccc}
\hline$v(\mathrm{mV} / \mathbf{s})$ & $\mathrm{E}_{\mathrm{pc}}(\mathrm{mV})$ & $\mathrm{i}_{\mathrm{pc}}(\mu \mathrm{A})$ & $\mathrm{E}_{\mathrm{pa}}(\mathrm{mV})$ & $\mathrm{i}_{\mathrm{pa}}(\mu \mathrm{A})$ & $\mathrm{i}_{\mathrm{pa}} / \mathrm{i}_{\mathrm{pc}}$ & $\mathrm{i}_{\mathrm{pc}} / v \tilde{0}^{1 / 2}$ & $\mathrm{i}_{\mathrm{pa}} / \mathrm{U}^{1 / 2}$ & $\Delta \mathrm{E}_{\mathrm{p}}(\mathrm{mV})$ \\
\hline 40 & 578 & 0.62 & 736 & 0.96 & 1.55 & 0.098 & 0.15 & 158 \\
60 & 580 & 0.79 & 740 & 1.35 & 1.71 & 0.10 & 0.17 & 160 \\
80 & 579 & 0.78 & 740 & 1.88 & 2.41 & 0.087 & 0.21 & 161 \\
100 & 580 & 0.75 & 735 & 2.28 & 3.04 & 0.075 & 0.22 & 155 \\
\hline
\end{tabular}


Table 3: Cyclic voltammetric data of Cu(II)-APPH chelate

\begin{tabular}{|c|c|c|c|c|c|c|c|c|c|c|c|c|}
\hline $\begin{array}{l}u \\
(\mathrm{mV} / \mathrm{s})\end{array}$ & $\begin{array}{c}E_{p c 1} \\
(m V)\end{array}$ & $\begin{array}{c}i_{p c 1} \\
(\mu A)\end{array}$ & $\begin{array}{c}E_{p c 2} \\
(m V)\end{array}$ & $\begin{array}{c}i_{p c 2} \\
(\mu A)\end{array}$ & $\begin{array}{c}E_{p a 1} \\
(m V)\end{array}$ & $\begin{array}{c}i_{p a 1} \\
(\mu A)\end{array}$ & $\begin{array}{c}E_{p a 2} \\
(m V)\end{array}$ & $\begin{array}{c}i_{p a 2} \\
(\mu A)\end{array}$ & $\mathrm{i}_{\mathrm{pa1}} / \mathrm{i}_{\mathrm{pc1}}$ & $\mathrm{i}_{\mathrm{pa2} 2} / \mathrm{i}_{\mathrm{pc} 2}$ & $\Delta \mathrm{E}_{\mathrm{p} 1}$ & $\Delta \mathrm{E}_{\mathrm{p} 1}$ \\
\hline 20 & -737 & -2.0 & -197 & -0.58 & -58 & 2.79 & 577 & 0.64 & 1.4 & 1.1 & 679 & 774 \\
\hline 40 & -810 & 2.24 & -227 & -0.91 & -43 & 4.07 & 599 & 0.81 & 1.8 & 0.94 & 767 & 826 \\
\hline 60 & -876 & 1.95 & -263 & -0.78 & -29 & 4.92 & 606 & 0.89 & 2.5 & 1.14 & 847 & 869 \\
\hline 80 & - & - & -591 & 0.367 & -14 & 5.08 & 628 & 0.91 & - & 2.4 & - & 1219 \\
\hline
\end{tabular}

evident that the molecule APPH bear three quaternary carbon atoms, labelled as 4, 5 and 6 . In the DEPT-135 spectrum of the molecule, the signals corresponds to these carbon atoms were totally absent, confirming that these peaks are definitely due to quaternary carbons. Since there were no methylene groups in the molecule, the DEPT 135 spectrum not displayed any inverse signals. In the HMQC spectrum of APPH (Figure 2), the ${ }^{1} \mathrm{Hnmr}$ signal was absent corresponds to the $\mathrm{C} 4$ (observed at $145.07 \mathrm{ppm}$ ), since this carbon atom is not bearing a proton. Similarly the corresponding ${ }^{1} \mathrm{Hnmr}$ signal was not appeared for $\mathrm{C} 6$ signal at ${ }^{13} \mathrm{Cnmr}$ axis. The corresponding ${ }^{13} \mathrm{C}$ contours for the proton signal appeared at $9.86 \delta$ was not present in the HMQC spectrum. This evidently establishes that this proton is not bearing a carbon atom and it is assigned for $\mathrm{NH}$ proton signal.

An intense IR peak appeared at $1593 \mathrm{~cm}$ ${ }^{1}$ can be assigned to the $\mathrm{C}=\mathrm{N}$ stretching vibration. $\mathrm{A}$ broad band displayed at $3265 \mathrm{~cm}^{-1}$ is due to $\mathrm{N}-\mathrm{H}$ frequency. $v_{\mathrm{C}=\mathrm{N}}$ was appeared at $1465 \mathrm{~cm}^{-1}$ and $\mathrm{C}-\mathrm{H}$ stretching frequencies was shown between 3030$3100 \mathrm{~cm}^{-1}$ and the bands appeared at 621 and

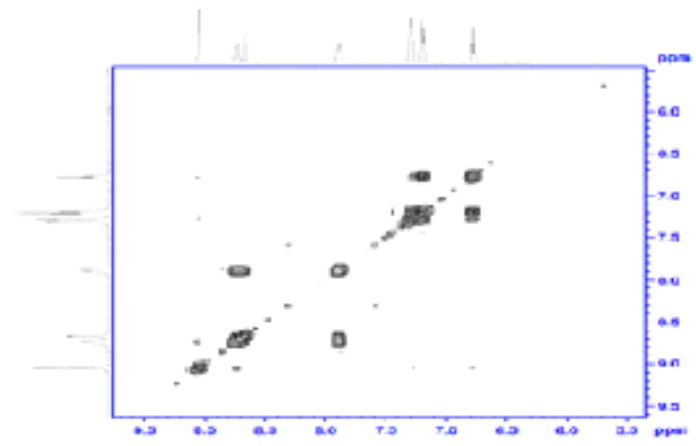

Fig. 1: COSY spectrum of APPH
$667 \mathrm{~cm}^{-1}$ can be considered as in-plane deformation mode of the pyridine ring. The important electronic transitions occurred in the molecules were observed at $32679 \mathrm{~cm}^{-1}$ and $29239 \mathrm{~cm}^{-1}$ which are attributed to $\pi \rightarrow \pi^{*}$ and $n \pi^{*}$ transitions respectively.

\section{Characterization of $\mathrm{Cu}$ (II) chelate}

Elemental analysis of the metal chelate: Metal \%16.82 (16.21); C\% 50.99 (51.96); H\% 4.33 (4.84); N\% 10.44 (10.69). Calculated values are represented in brackets. A square planar geometry was assigned to the $\mathrm{Cu}(\mathrm{II})$ chelate (Figure 3 ) since it displayed $\mu_{\text {eff }}$ of $1.97 \mathrm{BM}$ ( $\mathrm{d}^{9}$ system $)^{16-18}$, which was further confirmed by electronic spectroscopic studies. In the optical absorption spectrum, the chelate gave two bands at 27310 and $28998 \mathrm{~cm}^{-1}$ which are due to ${ }^{2} \mathrm{~B}_{1} \rightarrow{ }^{2} \mathrm{~A}_{1}$ and ${ }^{2} \mathrm{~B}_{1} \rightarrow{ }^{2} \mathrm{~B}_{2}$ transitions respectively in addition to intra ligand transitions. Non-electrolytic nature of the chelate was established by the molar conductance data in DMSO $\left(15 \Omega^{-1} \mathrm{~cm}^{2} \mathrm{~mol}^{-1}\right)$.

Interpretation of the IR spectral data was very helpful for the assignment of the correct probe of the ligand which will make coordinate bonds with

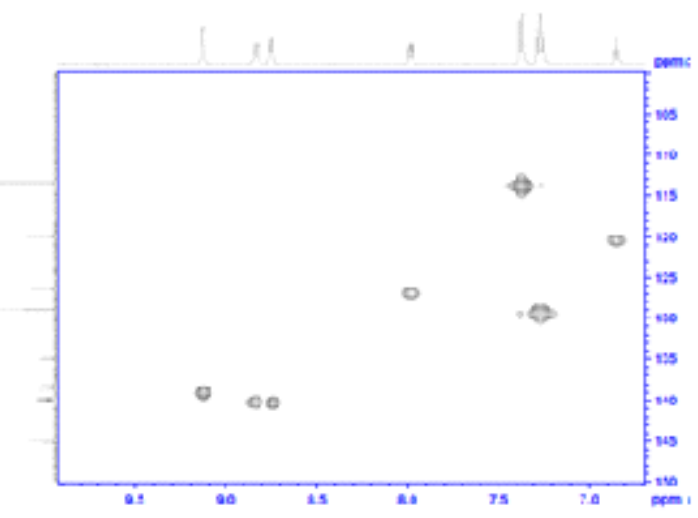

Fig. 2: HMQC spectrum of APPH 
the central metal ion in a chelate. The IR spectrum of the phenylhydrazone exhibited a peak at $1593 \mathrm{~cm}^{-}$ 1 , which was due to the stretching vibration of azomethine group. The $v_{\mathrm{C}=\mathrm{N}}$ of chelate was lowered to $1579 \mathrm{~cm}^{-1}$ which is an indication of the coordination of azomethine nitrogen. A confirmatory<smiles>CC(=O)O[Al](Nc1ccccc1)N(C)Cc1cccnc1</smiles>

Fig. 3: Structure of $\mathrm{Cu}(\mathrm{II})$ chelate

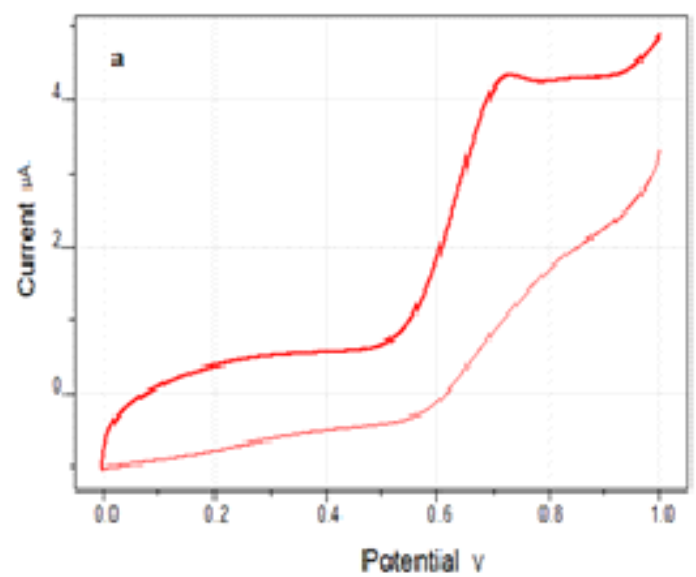

evidence for the coordination of heterocyclic nitrogen was also obtained from the IR spectral data. The in-plane deformation modes of pyridine ring shown by the ligand at 621 and $667 \mathrm{~cm}^{-1}$ respectively shifted to 625 and $687 \mathrm{~cm}^{-1}$ in chelate, suggesting the coordination of the hetero aromatic nitrogen to the metal ${ }^{19-20}$. Appearance of new bands at 434 and $411 \mathrm{~cm}^{-1}$ respectively, is an indication of coordination of the heteroaromatic nitrogen and azomethine nitrogen of the ligand $\mathrm{APPH}$ to the central metal ion. The IR spectrum of $\mathrm{Cu}$ (II) chelate displayed asymmetric and symmetric stretching frequencies $\mathrm{C}-\mathrm{O}$ bond of acetate ion at around 1597 and $1423 \mathrm{~cm}^{-1}$, respectively showing a difference of about $150 \mathrm{~cm}^{-1}$, which indicates the monodentate behaviour of acetate.

\section{Cyclic voltammetric studies on 3-acetylpyridine phenylhydrazone}

Figure $4 \mathrm{a}$ and $4 \mathrm{~b}$ display the cyclic

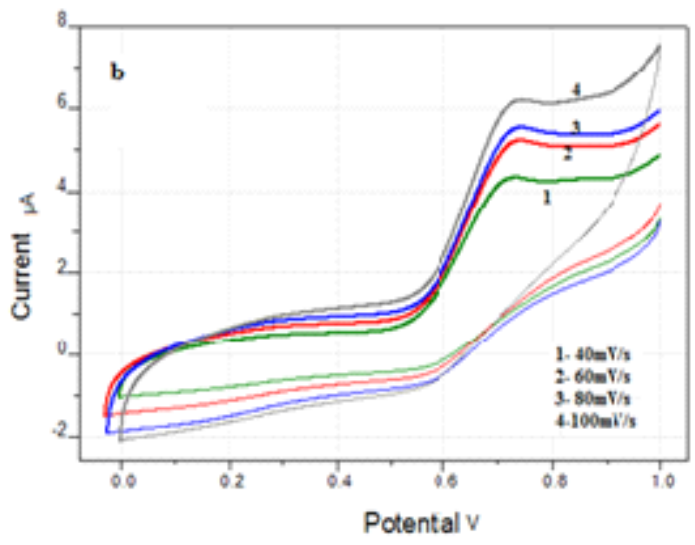

Fig. 4: Cyclic voltammogram of APPH a) at scan rate of $40 \mathrm{mV} / \mathrm{s}$ b) at scan rates $40-100 \mathrm{mV} / \mathrm{s}$

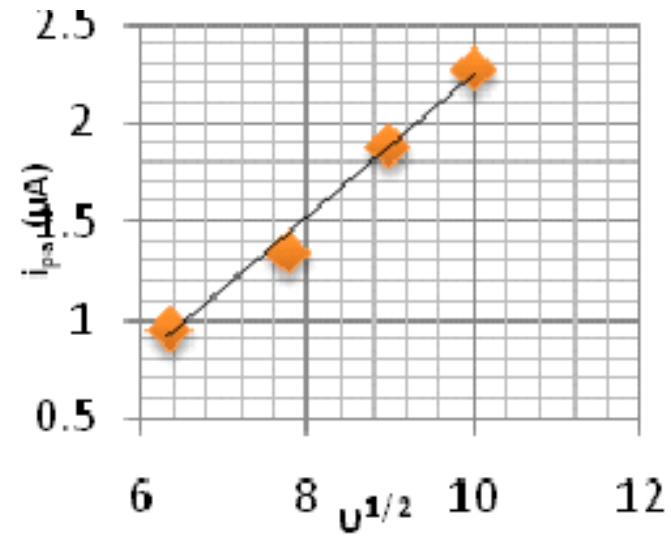

Fig. 5: The $\mathrm{i}_{\mathrm{pa}}-v^{1 / 2}$ curves of Phenyl hydrazone APPH voltammogram of the phenylhydrazone $\mathrm{APPH}$ at scan rate $40 \mathrm{mV} / \mathrm{s}$ and overlay contours of the voltammograms at various scan rates respectively. The CV diagram of APPH exhibited one reduction and oxidation peak and the redox couple behaved more close to a reversible system. The peak potentials $\left(E_{p}\right)$ were independent of the scan rate, suggesting the behaviour of the reversible system. The peak separation $\left(E_{p a}-E_{p c}\right)$ was comparable with the values of reversible redox couples and was independent on the rate of sweep. But the ratio of peak heights was greater than one and showed gradual rise with the scan rate. The cathodic peak current was not strictly proportional to the square 
root of sweep rate, but the anodic current exhibited fair proportionality to $v^{1 / 2}$ (Figure 5). Even though, some parameters emphasize the reversibility of the redox process, the actual electrochemical response of this system fall in the quasi reversible spectrum of compounds. The voltammetric data of the compound APPH is provided in Table 2.

\section{Cyclic voltammetric studies on Cu(II)-APPH} chelate

Cyclic voltammogram of $\mathrm{Cu}(\mathrm{II})-\mathrm{APPH}$ chelate at scan rate $20 \mathrm{mV} / \mathrm{s}$ is provided in Figure 6. In the forward scan, the voltammogram has two well defined cathodic waves with first peak $\left(\mathrm{E}_{\mathrm{pc} 1}\right)$ situated at more negative cathodic potential and the second peak appeared at a less cathodic potential.

As the sweep increased both cathodic peaks were shifted to more negative potentials and at higher scan rates the $\mathrm{E}_{\mathrm{pc1}}$ peak was disappeared.

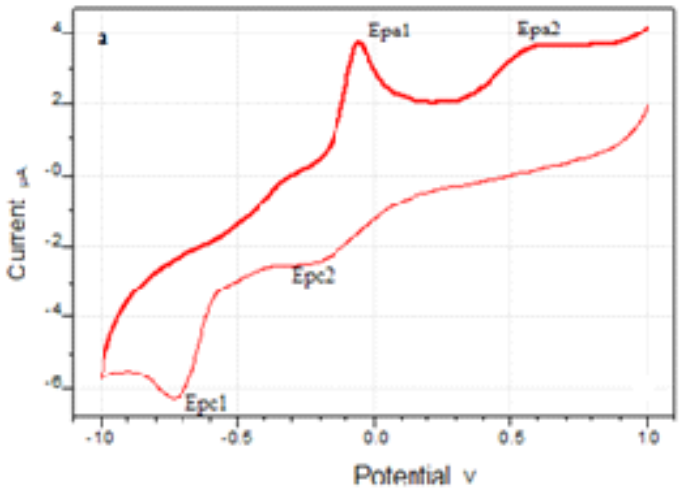

On reverse scan, two oxidation peaks were exhibited in the cyclic voltammogram, whose potentials are designated as $\mathrm{E}_{\mathrm{pa} 1}$ and $\mathrm{E}_{\mathrm{pa} 2}$. $\mathrm{E}_{\mathrm{pa} 1}$ and $E_{p a 2}$ are the genuine counter peaks of cathodic peaks $E_{p c 1}$ and $E_{p c 2}$ respectively. Both counter peaks were shifted to more positive potential as the scan rate was increased. The peak separation values of cathodic and anodic peaks suggest the quasi reversible nature of the redox system. Cyclic voltammetric data of $\mathrm{Cu}(\mathrm{II})-\mathrm{APPH}$ chelate is given in Table 3. Taking into consideration the cyclic voltammetric response of $\mathrm{Cu}$ (II)-APPH chelate, one can propose the mechanism of electrochemical reactions as follows. The first cathodic curve can be assigned to the cathodic reduction of $\mathrm{Cu}(\mathrm{II})$-chelate to the $\mathrm{Cu}(\mathrm{I})$-chelate in a quasi reversible mechanism, since there is a negative shift to cathodic peak potential with increase in the scan rate.

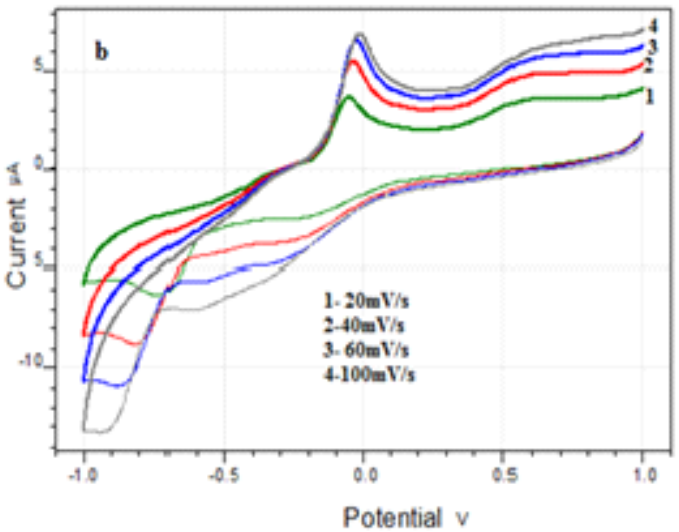

Fig. 6: Cyclic voltammogram of $\mathrm{Cu}(\mathrm{II})-\mathrm{APPH}$ chelate a) at scan rate of $20 \mathrm{mV} / \mathrm{s}$ b) at scan rates $20-80 \mathrm{mV} / \mathrm{s}$

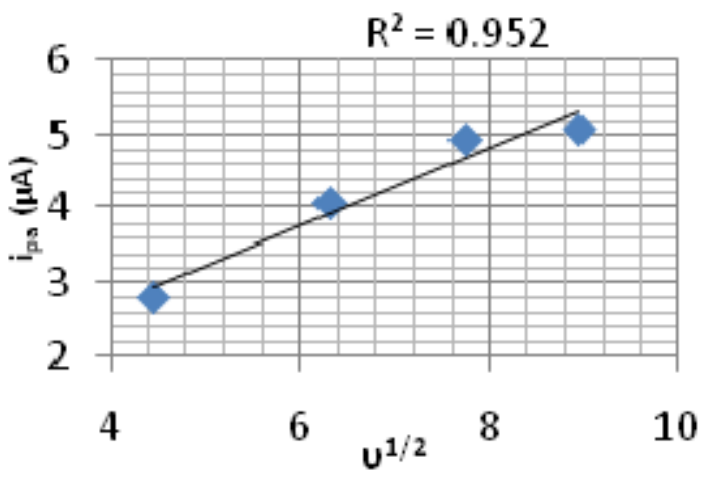

Fig. 7: The $\mathrm{i}_{\mathrm{pa} 1}-\mathrm{v}^{1 / 2}$ curves of $\mathrm{Cu}(\mathrm{II})-$ APPH chelate

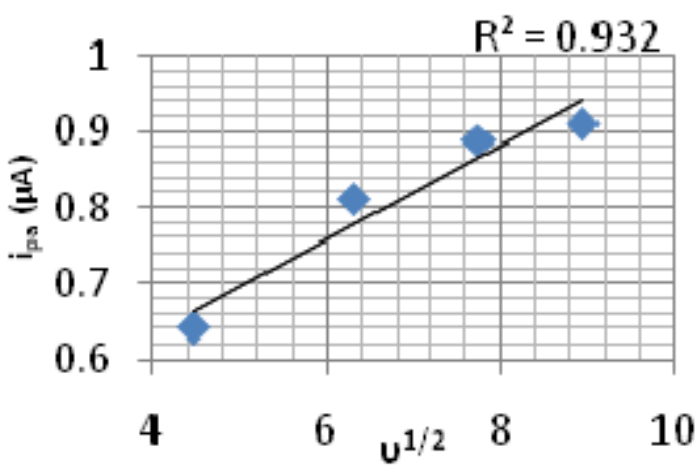

Fig. 8: The $i_{\mathrm{pa} 2}-v^{1 / 2}$ curves of $\mathrm{Cu}(\mathrm{II})-$ APPH chelate 
The second cathodic peak, which arise in the more negative potential to that of the first reduction peak is assignable to the reduction of $\mathrm{Cu}(\mathrm{I})$-chelate to the $\mathrm{Cu}(0)$-chelate. Since the $\mathrm{E}_{\mathrm{pc} 2}$ was also moved to the higher negative potentials with the scan rate, quasi reversible nature of the electrode process can be assumed. The peak height was not proportional to the square root of scan rate. The stability of $\mathrm{Cu}(0)$-chelate is very low and the ligand molecules may or may not detach (decomplexation) from the metal atom within a short span. So the concentration of $\mathrm{Cu}(0)$-chelate in the immediate vicinity of the carbon electrode will be very low. The first anodic peak in $\mathrm{CV}$ can be attributed to the anodic oxidation of $\mathrm{Cu}(0)$-chelate, which is the counter peak of $\mathrm{E}_{\mathrm{pc} 1}$. The height of this anodic peak was high and showed proportionality with $v^{1 /}$ 2 (Figure 7) which may be due to the combined oxidation of unstable $\mathrm{Cu}(0)$-chelate and free $\mathrm{Cu}$ atoms adjacent to the electrode. The second anodic peak appeared at high positive potential can be assigned to the anodic oxidation of $\mathrm{Cu}(\mathrm{I})$-chelate to $\mathrm{Cu}(\mathrm{II})$-chelate in a quasi reversible manner. This peak was shifted to more positive potentials with the scan rate and the anodic current was proportional to $v^{1 / 2}$ (Figure 8 ). The overall mechanism can be represented as follows.

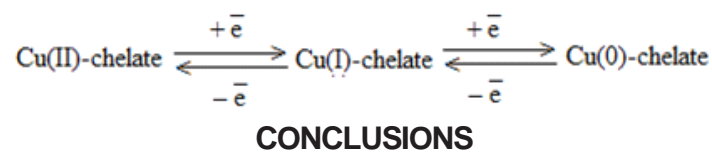

Novel heterocyclic phenylhydrazone (APPH) and its copper chelate were synthesized.

Structure of the ligand and chelate were established by various analytical methods and it was proved that a 1:1 stoichiometry exist between the ligand and the metal ion. Square planar geometry was suggested for the chelate.

The electrochemical behaviour of the ligand and chelate were studied using cyclic voltammetry. One redox couple was shown by APPH, while the chelate displayed two redox couples in the voltammogram.

The quasi reversible nature of the redox process was observed in both APPH and its $\mathrm{Cu}(\mathrm{II})$ chelate

\section{REFERENCES}

1. Prakash, A.; Singh, B. K.; Bhojak, N.; Adhikari, D.; Spectrochim. Acta. 2010, 76, 356-362.

2. Siddiqi, K. S.; Kureshy, R. I.; Khan, N. H.; Tabassum, S.; Zaidi, S.; Inorg. Chem. Acta. 1988, 151(2), 95-100.

3. Laidler, D. A.; Miller, D. J.; J. Organomet. Chem. 1984, 270, 121-129.

4. Zhu, L.; Li, Chenn, H.; Song, F.; Zhu, X.; Hua. Shif. Dax. Xue. Zirank. 2003, 37, 499-502.

5. Dash, B.; Mahapatra, P. K.; Panda, D.; Patnaik, J. M.; J. Indian Chem. Soc. 1984, 61, 10611064.

6. Rao, N. R.; Rao, P. V.; Reddy, G. V.; Ganorkar, M. C.; Indian J. Chem.1987, 26A, 887-890.

7. Mishra, P.; Gupta, P. N.; Shakaya, A. K.; J. Indian Chem. Soc. 1991, 68, 539-541.

8. Srinivasa. V.; Srivastava, S. K.; Mishra, A. P.; J. Indian Chem. Soc. 1995, 72, 47-78.

9. Dhakrey, R.; Saxena, G.; J. Indian Chem. Soc. 1987, 64, 685-686.

10. Rîmbu, C.; Danac, R.; Pui, A.; Chem. Pharm. Bull. 2014, 62 (1), 5-12.

11. Vinod, P. R.; Joby, T. K.; Shaju, K. S.; Aby, P.;
Res. Chem. Intermed. 2014, 40, 2689-2701.

12. Shaju, K. S.; Joby, T. K.; Vinod. P. R.; Oriental. J. Chem. 2014, 30(2), 807-813 .

13. Joshi, K. T.; Pancholi, A. M.; Oriental. J. Chem. 2000, 16, 287-290.

14. Singh K.; Barwa, M. S.; Eur. J. Med. Chem. 2006, 41, 147-152.

15. Ruiz, E.; Alemany, P.; Alvarez, S.; Cano, J.; Inorg. Chem. 1997, 36(17), 3683-3688.

16. Biradar, N. S.; Havinale, B. R.; Inorg. Chim. Acta 1976, 17, 157-160.

17. Coles, R. B.; Harris, C. M.; Sinn, E.; Inorg. Chem. 1969, 8 (12), 2607-2612.

18. Mendes, I. C.; Moreira, J. P.; Mangrich, A. S.; Balena, S. P.; Rodrigues, B. L.; Beraldo, H.; Polyhedron, 2007, 26, 3263-3270.

19. Mendes, I. C.; Moreira, J. P.; Speziali, N. L.; Mangrich, A. S.; Takahashi, J. A.; Beraldo, H.; J. Braz. Chem. Soc. 2006, 17, 1571-1577.

20. Recio-Despaigne, A. A.; Da Costa, F. B.; Piro, O. E.; Castellano, E. E.; Louro, S. R. W.; Beraldo. H.; Polyhedron, 2012, 38, 285-290. 